\title{
Association of Sedentary Behaviour and Mental Health among Young Adults: A Cross-Sectional Study
}

\author{
Nizar Abdul Majeed Kutty ${ }^{1 *}$, Muhammed Abdulrazzak Jabbar ${ }^{1}$, ReshmaPraveen $^{2}$, Choi Yoke Lee $^{3}$ \\ ' Senior Lecturer, Faculty of Medicine \& Health Sciences, University Tunku Abdul Rahman, Malaysia \\ ${ }^{2}$ Lecturer, Faculty of Medicine \& Health Sciences, University Tunku Abdul Rahman, Malaysia \\ ${ }^{3}$ Year III BPT Student, Faculty of Medicine \& Health Sciences, University Tunku Abdul Rahman, Malaysia
}

\begin{abstract}
:
Sedentary behaviour contributes to adverse physical health outcomes in youth. Although evidence for the relationship between sedentary behaviour and mental health outcomes is emerging, little is known regarding risk of psychological distress and low self-esteem. The purpose of this study was to investigate the association of sedentary behaviour with psychological distress and self-esteem in a well-characterised young adult population after controlling for a wide range of potential confounders. We adopted a cross-sectional study design. A sample of 352 participants, 208(59.1\%) females and 144(40.9\%) males responded to a survey. Participants were recruited from University Tunku Abdul Rahman, Malaysia. Sedentary behaviour of the participants was determined by Sedentary Behaviour Questionnaire. Kessler Psychological Distress Scale and Rosenberg Self-Esteem Scale were used to measure psychological distress and global self-esteem respectively. Analysis of sedentary behaviour demonstrated that participants have high sedentary times. The highest sedentary behaviour engaged by the participants was doing paperwork or computer work, followed by sitting, listening to music and sitting and talk on a phone. Participants spent least time playing musical instruments. Multi regression analysis was performed to determine the level of significance. Sedentary behaviour showed a statistically significant association with psychological distress and self-esteem. Sedentary behaviour can lead to mental health problems in young adults. These findings have a number of important implications for policy and practice. They highlight the need to ensure that young people have appropriate and timely access to evidence based services and interventions across the continuum. Further high-quality longitudinal or interventional research is needed to confirm findings and determine the direction of these relationships.
\end{abstract}

Keywords: Sedentary behaviour; Psychological distress; Self-esteem; Youth

\section{Introduction}

Time spent in sedentary behavior has emerged as a potentially important indicator of health in youth independent of achieving sufficient physical activity. Sedentary behavior can be defined as any waking behavior characterized by a low energy expenditure (i.e., 1.5 resting metabolic equivalents) while in a sitting or reclining posture ${ }^{[1]}$. Research shows the amount of time young people spend in sedentary behaviours has increased in recent years, and while this includes TV time, it is a dramatic increase in other types of screen time such as computers and video games that appears to be driving the trend ${ }^{[2]}$. Only one-third of youth worldwide are estimated to be sufficiently physically active ${ }^{[3]}$, whereas sedentary behavior has increased during the last few decades ${ }^{[4]}$.

Spending too much time in sedentary behaviours differs from not getting enough physical activity. In other words, being too sedentary is distinct from not meeting physical activity guidelines ${ }^{[5]}$. This risk over time may be independent of physical activity. A European study led by Spanish researchers has shown how the proportion of young people who watch television and play on the computer for more than two hours per day doubles at the weekend and while boys opt for video games, teenage girls prefer to surf the net ${ }^{[6]}$. Having a games console or television in the bedroom triples the risk of exceeding the health recommendations to not spend more than two hours per day watching television. However, having a computer in the bedroom reduces the risk of excessive television watching ${ }^{[7]}$. Children who spend longer than two hours in front of a computer or television screen are more likely to suffer psychological difficulties, regardless of how physically active they are ${ }^{[8]}$. Evidence suggests sedentary behaviour is associated with increased risk of developing various chronic diseases e.g. overweight and obesity, type 2 diabetes $^{[9]}$, cardiovascular disease ${ }^{[10]}$, and various cancers.
Received Date: March 24, 2017 Accepted Date: July 09, 2018 Published Date: July 13, 2018

*Corresponding author: Nizar Abdul Majeed Kutty, Senior Lecturer, Faculty of Medicine \& Health Sciences, University Tunku Abdul Rahman, Selangor, 43000, Malaysia, Tel: 0060163702375 ;

E-mail: nizarkualalumpur@gmail.com

Citation: Majeed Kutty, N.A., et al. Association of Sedentary Behaviour and Mental Health among Young Adults: A Cross-Sectional Study. (2018) J diab Obes 5(1): 31- 36.

Copyright: (C) 2018 Majeed Kutty, N.A. This is an Open access article distributed under the terms of Creative Commons Attribution 4.0 International License. 
Citation: Majeed Kutty, N.A., et al. Association of Sedentary Behaviour and Mental Health among Young Adults: A Cross-Sectional Study. (2018) J diab Obes 5(1): $31-36$.

However, reviews of prospective studies suggest that there is yet insufficient or no evidence to conclude relationships between sedentary behaviour and certain mental health outcomes.It has been suggested that a positive relationship exists between most sedentary behaviors and depression within some population groups like women and adolescents ${ }^{[11]}$. Though mental health consequences of sedentary behavior in children and adolescents have been identified however, like that of the adult literature, reviews of prospective studies in young people suggest that there still remains insufficient evidence to conclude associations between sedentary behavior and some mental health indicators like psychological distress and self-esteem. Self-esteem, as an overall reflection of an individual's self-worth, encompasses beliefs about oneself as well as an emotional response to those beliefs. Representing the capacity to feel worthy of happiness and be able to successfully address life challenges, self-esteem is an important determinant of mental health and development. Research has shown key differences between individuals with high and low self-esteem. For example, people with high self-esteem focus on growth and improvement, whereas people with low self-esteem focus on not making mistakes in life. Although boys and girls report similar levels of self-esteem during childhood, a gender gap emerges by adolescence, in that adolescent boys have higher self-esteem than adolescent girls ${ }^{[12]}$. Low self-esteem is associated with a number of modifiable risk factors including obesity, television time, team sports participation, overweight and obesity ${ }^{[13]}$. Young people's 'lifestyles' have changed radically since the mid- $20^{\text {th }}$ century. In particular, they have become more leisure or entertainment oriented. Another significant aspect of changing youth lifestyles is their increasing involvement with electronic media, involving massive increases in computer and video game use. Computer games have also evolved, the current generation allowing more graphic depictions of violence, and having the ability to connect players virtually ${ }^{[14]}$. Two U.S. based studies examining the associations between screen time, sitting time and depression among overweight minority women ${ }^{[15]}$ and Latino adults ${ }^{[16]}$ respectively. A study focused on physical self-perceptions among adolescent girls reported small direct associations between sedentary behaviors and 'sports competence' and 'physical conditioning' but not global self-esteem ${ }^{[17]}$. Alternatively, some evidence from studies suggests that it is not the total time spent in sedentary behavior that is important. Rather, specific sedentary behaviors may contribute to mental health in different ways. In this case, exposure to different sedentary behaviors, such as talking to friends or playing violent video games, might promote mental health positively or negatively in undetermined ways. Moreover, the ubiquitous nature of recreational screen time may mask 'effects' for TV viewing and computer use. A study conducted in Australia found that time spent in specific screen based recreation was associated with self-esteem in adolescent girls living in low-income communities ${ }^{[18]}$. In the light of these inconclusive findings; further research is clearly indicated to examine the direction of associations between sedentary behavior and mental health outcomes and to identify how individual sedentary behaviors relate to mental health outcomes in different populations. Knowledge on the determinants of SB in youth is necessary to shape future intervention development to reduce SB and prevent its complications. Thus the aim of this study is to investigate the association between sedentary behavior and mental health outcomes; psychological distress and self-esteem.

\section{Methods and Materials}

This cross-sectional study included a sample of young adults to determine the association of sedentary behaviour and mental health outcomes; psychological stress and self-esteem. The participants of this study were students recruited from University Tunku Abdul Rahman (UTAR), Sungai Long Campus, Malaysia. A total of 352 students participated in this study. Both males and females of $18-25$ years were included. Subjects who suffer from any form of cancer, thyroid disease, congenital malformations, skeletal deformities and those on walking aids were excluded. This study was approved by the Scientific and Ethical Review Committee of UTAR. Participants were informed regarding the procedure and confidentiality was ensured. Out of 352 participants, 208(59.1\%) were females and 144(40.9\%) were males. Informed consent was obtained from all participants. Demographic data was gathered using a self-designed questionnaire.

\section{Outcome measures}

The sedentary behaviour questionnaire (sbq): The SBQ was designed to assess the amount of time spent doing 9 behaviors (watching television, playing computer/video games, sitting while listening to music, sitting and talking on the phone, doing paperwork or office work, sitting and reading, playing a musical instrument, doing arts and crafts, sitting and driving/riding in a car, bus, or train). The 9 items were completed separately for weekdays and weekend days. Wording for weekday reporting was, "on a typical weekday, how much time do you spend (from when you wake up until you go to bed) doing the following?" A recent systematic review suggests that self and proxy-report tools generally display acceptable reliability and validity in assessing sedentary behavior ${ }^{[19]}$.

Kessler psychological distress scale (K10): The 10-item Kessler Psychological Distress Scale (K10) is a short measure of non-specific psychological distress. Each question pertains to an emotional state and each has a five-level response scale. The $\mathrm{K} 10$ is frequently used in population health surveys, especially in situations where it is not feasible to include a long diagnostic interview to assess mental disorders. This instrument uses a consumer self-report measure making it a desirable method of assessment because it depends on the clinician's genuine pursuit to collect information about the patient's current condition. The instrument can be self-administered or interviewer-administrated and consumers' privacy should be insured when using this instrument. The ending kappa and weighted kappa scores ranged from 0.42 to 0.74 , indicating that the $\mathrm{K} 10$ is a moderately reliable instrument ${ }^{[20]}$.

The rosenberg self-esteem scale: The Rosenberg Self-Esteem Scale is a tool for assessing global self-esteem. Ten statements are included in the self-report measure that pertains to selfworth and self-acceptance. It has a four-point scale ranging from "strongly agree" to "strongly disagree." The items were selected as a Guttman scale with 7 "contrived items." The Rosenberg 
Self-Esteem Scale presented high ratings in reliability areas; internal consistency was 0.77 , minimum Coefficient of Reproducibility was at least $0.90^{[21]}$.

Statistical analysis: SPSS software - version 22 was used to analyse the data. A standard multiple regression analysis was used to determine the relationship between the sedentary behaviour and psychological distress level and self-esteem level among university students. In order to score and analyse the results of the SBQ, sedentary behaviour was assessed separately for weekdays and weekends.

\section{Results}

A total of 352 participants took part in this study. The age group of 18 to 21 had highest participants $(76.4 \%)$. Majority of the participants were females $(59.1 \%)$. The mean of the duration of sleep was 7.19 hours and mean for sedentary behaviour on weekday (SBWD) was 8.04 hours while sedentary behaviour on weekend (SBWK) was 9.04 hours. Most of the participants had moderate self-esteem and $61.6 \%$ of young adults suffer anxiety. Doing paperwork or computer work was the sedentary behaviour demonstrated by highest number of participants on weekdays followed by sitting, listening to music. On weekend, sitting and listen to music showed the highest participation, followed by doing paperwork and watching television. There is a positive significant correlation between the sedentary behaviour of the participants and their mental health as shown in the Table 1 meaning the less sedentary life style the better the mental health the participants would be. On the other hand, there is reverse significant correlation between the sedentary behaviour during the week day meaning, the more active participants are during the weekdays the better self-esteem would be.

Table 1: Correlation of sedentary behavior of participants with their mental health and self-esteem.

\begin{tabular}{|l|c|l|l|l|}
\hline & $\begin{array}{l}\text { Sedentary Behaviour Week } \\
\text { Days 8.04 (4.68) mean (sd) }\end{array}$ & $\mathbf{n}$ & $\begin{array}{l}\mathbf{r} \\
\text { value }\end{array}$ & $\begin{array}{l}\text { p- } \\
\text { value }\end{array}$ \\
\hline $\begin{array}{l}\text { Mental } \\
\text { Health }\end{array}$ & $18.09(4.13)$ & 352 & 0.146 & $0.003^{*}$ \\
\hline Self Esteem & $22.03(5.97)$ & 352 & -0.135 & $0.006^{*}$ \\
\hline
\end{tabular}

*Pearson correlation was performed, $r=$ correlation coefficient, level of significant at $\mathrm{p}<0.05$.

A standard multiple regression was run to predict mental health of the participants from their sedentary behaviour on weekdays scale score, age, gender, and the course they study. There was linearity as assessed by partial regression plots and a plot of studentized residuals against the predicted values. There was independence of the residuals, as assessed by Durbin-Watson statistics of 1.848. There was homoscedasticity, as assessed by visual inspection of a plot of studentized results versus unstudentized predicted values. There was no evidence of multicollinearity, as assessed by tolerance values greater than 0.1 . The assumption of normality was met as assessed by Q-Q plot. The multiple regression model statistically significantly predicted mental health status of the participants $\mathrm{F}(4,351)=6.787$, $\mathrm{p}<$ 0.05 , adjusted $\mathrm{R}^{2}=0.062$. The sedentary behaviour score correlated positively and significantly predicting the mental health status of the participants with $\mathrm{p}<0.05$ (Table: 2 ). In addition to that, gender of the participants showing inverse correlation and significantly predicting the mental health status with $\mathrm{p}<0.05$ and that means the females are showing better mental health status compared to the males.

Table 2: Predictors of mental health status of the participants.

\begin{tabular}{|l|c|c|c|}
\hline & B & t & p-value \\
\hline Intercept & 25.004 & 19.44 & 0.000 \\
\hline Sedentary Behaviour on week days & 0.226 & 3.337 & $0.001^{*}$ \\
\hline Age & -0.544 & -0.815 & 0.416 \\
\hline Gender & -2.279 & -3.543 & $<0.001^{*}$ \\
\hline Faculty & -0.497 & -1.659 & 0.098 \\
\hline
\end{tabular}

*Standard multiple regression analysis, level of significant at $\mathrm{p}<0.05$.

A standard multiple regression was run (Table 3) to predict mental health of the participants from their sedentary behaviour on week days scale score, age, gender, and course they study. There was linearity as assessed by partial regression plots and a plot of studentized residuals against the predicted values. There was independence of the residuals, as assessed by a Durbin-Watson statistics of 1.848. There was homoscedasticity, as assessed by visual inspection of a plot of studentized results versus unstudentized predicted values. There was no evidence of multicollinearity, as assessed by tolerance values greater than 0.1 . The assumption of normality was met as assessed by Q-Q plot. The multiple regression model statistically significantly predicted Mental health status of the participants $\mathrm{F}(4,351)=$ $6.787, \mathrm{p}<0.05$, adjusted $\mathrm{R}^{2}=0.062$. The sedentary behaviour score correlated positively and significantly predicting the mental health status of the participants with $p<0.05$. In addition to that, gender of the participants showing inverse correlation and significantly predicting the mental health status with $\mathrm{p}<0.05$ and that means the females are showing better mental health status compared to the males.

Table 3: Predictors of self-esteem status of the participants.

\begin{tabular}{|l|c|c|c|}
\hline & B & t & p-value \\
\hline Intercept & 17.774 & 19.67 & $<0.001^{*}$ \\
\hline Sedentary Behaviour on week days & -0.126 & -2.687 & $0.008^{*}$ \\
\hline Age & 1.186 & 2.528 & $0.012^{*}$ \\
\hline Gender & 0.329 & 0.729 & 0.466 \\
\hline Faculty & -0.340 & -1.616 & 0.107 \\
\hline
\end{tabular}

*Standard multiple regression analysis, level of significant at $\mathrm{p}<0.05$.

A standard multiple regressions was run (Table 3) to predict the self-esteem status of the participants from their sedentary behaviour on week day scale score, age, gender, and course they study. There was linearity as assessed by partial regression plots and a plot of studentized residuals against the predicted values. There was independence of the residuals, as assessed by a Durbin-Watson statistics of 2.063. There was homoscedasticity, as assessed by visual inspection of a plot of studentized results versus unstudentized predicted values. There was no evidence of multicollinearity, as assessed by tolerance values greater than 0.1 . The assumption of normality was met as assessed by Q-Q plot. The multiple regression model statistically sig- 
Citation: Majeed Kutty, N.A., et al. Association of Sedentary Behaviour and Mental Health among Young Adults: A Cross-Sectional Study. (2018) J diab Obes 5(1): $31-36$.

nificantly predicted mental health status of the participants $\mathrm{F}(4$, $351)=4.151, \mathrm{p}<0.05$, adjusted $\mathrm{R}^{2}=0.035$. There is an inverse correlation between sedentary behaviour score and self-esteem score showing that the more active life the participants had, the better self-esteem they have and sedentary behaviour is significantly predicting the self-esteem status of the participants with $\mathrm{p}<0.05$. In addition to that, age of the participants showing positive correlation and significantly predicting the self-esteem status with $\mathrm{p}<0.05$ which means the younger groups are having better self-esteem status compared to the older groups.

\section{Discussion}

This study was aimed to determine the association of sedentary behaviour and mental health. Psychological distress and self-esteem were studied as attributes of mental health. Previous studies focusing on sedentary behaviour were largely focused on children, working adults, and older adults.

Rosenberg et al. found that the average sedentary time on weekdays was 9.65 hours/day and weekends were 9.8 hours/ day ${ }^{[22]}$. The current study found an average total sedentary time of 8.04 hours/day on weekdays and 9.04 hours/day on weekends.

The findings of this study concluded that majority of the participants spent more time on doing paperwork or computer work during weekday and weekend. Participants might have a lot of readings, assignments, essays and other projects which require them to sit and focus in order to complete. Meanwhile, the computer use will be increased to explore the important information to complete their tasks. The ease of the internet encourages institutions of higher learning to employ the internet to support students' learning. The web is known as one of the main sources of information. It is very popular among users which include professionals, students, household, clerk, and others ${ }^{[23]}$. The web provides information that serves many purposes including research ${ }^{[24]}$, and entertainment ${ }^{[25]}$. Next to paper work and computer use participants' sedentary time was attributed to sit and listen to music on radio, tapes or CDs. Many students listen to music to alleviate the emotional effects of stress and anxiety when engaged in complex cognitive processing, such as studying for a test, completing homework assignments, or while reading and writing. Research demonstrating the effects of music on performance is well documented, but has shown ambiguous evidence on this matter. In studies conducted to learn about the effects of musical distraction on cognitive task performance, the findings have demonstrated the idea of music improving cognitive performance ${ }^{[26]}$. Researchers assume that this might be the reason that listening to music was one of the popular sedentary behaviours that university students involved on weekday and weekend as music has the power of creating an atmosphere that they wish to have by listening to different frequency and sound of the music. The least popular sedentary behaviour among participants was playing musical instruments. Only 63 and 70 participants involved in playing musical instruments during weekday and weekend time respectively. Duration of less than 15 minutes was spent on playing musical instruments on a particular day. Many youngsters lose interest in learning music when they reach their teenage years and the formal syllabus and examination patterns in music schools keep students away. Most of the university students live in hostels. A squeeze on supply coupled with dramatically increased rents in the capital mean pressure force them to share rooms with peers. This might be another reason not to play musical instruments.

It has been hypothesized that sedentary behaviour may lead to psychological distress through biological pathways. Studies show that engaging in screen-based entertainment, such as video gaming, has been shown to increase the arousal of the central nervous system ${ }^{[27]}$, which could potentially lead to increased levels of anxiety. On the other hand, it could be hypothesized that those with poor mental health tend to engage in sedentary behaviour more than those without the illness.

The findings of these study state female participants are showing better mental health status compared to the males. We did not replicate the findings in several studies on gender differences in mental health and mental illness among young people which found young women are more likely to report feeling constantly stressed than young men. Our findings may differ from other studies due to the cross-sectional design of our study or social factors, such as the degree to which women are excluded from schooling, or from participation in public life, affect their knowledge about health problems and how to prevent and treat them. Gender differences in different types of mental illness are influenced by cultural backgrounds and factors indicative of gender disadvantage which are negligible in Malaysian society.

Considering the positive effect of physical activity on weight status and self-esteem in adolescents ${ }^{[28]}$, this study sought to determine the relationship between sedentary behaviour and self-esteem. The relationship between sedentary time and self-esteem was significant $(p>0.05)$. As this study was cross-sectional, we cannot determine whether participants with low self-esteem engage in higher amounts of SB, or whether it is higher amounts of SB that contributes to lower self-esteem in this cohort. Similarly, another study found that one risk factor for becoming a pathological gamer was lower social competence. It is possible that adolescents who find it difficult to interact with peers or suffer from anxiety or other social phobias choose to withdraw to more solitary pursuits such as screen-based activities ${ }^{[29]}$. Further research is required to explore adolescent screen-based multitasking behavioural patterns and the potential consequences. There are some limitations that should be noted. The current study would have found greater success if we were able to use the best objective tool of an accelerometer, providing researchers with a more detailed picture of the total sedentary time of the young population.

\section{Conclusion}

This study delivers a comprehensive description of the relationship between sedentary behaviour and attributes of mental health; psychological distress and self-esteem in young adults. The World Health Organization defines health promotion as "the process of enabling people to increase control over, and to improve, their health. It moves beyond a focus on individual behaviour towards a wide range of social and environmental interventions" and decreasing sedentary behaviour is no exception. Through environmental changes on university campuses, research can serve to increase the health of the young adults, an important sub-group of the population in order to increase the 
health of all Malaysians. Our findings are indicative of the complex nature of these relationships and reveal a need for further longitudinal and intervention-based research in the field.

Funding: This study was not supported by any person or agency.

Disclosure: None of the Authors have any potential conflict of interest associated with this research.

Conflict of Interest: All Authors state that there are not conflicts of interest related to the present paper.

\section{References}

1. Sedentary Behaviour Research Network. Standardized use of the terms "sedentary" and "sedentary behaviours". (2013) Ment Health Phys Act 6(1): 55-56.

Pubmed | Crossref | Others

2. Rideout, V.J., Foehr, U.G., Roberts, D.F. Generation M2: media in the lives of 8 to 18 -year-olds. A Kaiser Family Foundation Study.

Pubmed $\mid$ Crossref $\mid$ Others

3. Ekelund, U., Tomkinson, G., Armstrong, N. What proportion of youth are physically active? Measurement issues, levels and recent time trends. (2011) Br J Sports Med 45(11): 859-865.

Pubmed | Crossref | Others

4. Pate, R.R., Mitchell, J.A., Byun, W., et al. Sedentary behaviour in youth. (2011) Br J Sports Med 45(11): 906-913. Pubmed | Crossref | Others

5. Pate, R., O'Neill, J., Lobelo, F. The evolving definition of "sedentary". (2008) Exerc Sport Sci Rev 36(4): 173-178. Pubmed | Crossref | Others

6. Rey-Lopez, J.P., Vicente-Rodriguez, G., Ortega, F.B., et al. Sedentary patterns and media availability in European adolescents: The HELENA study. (2010) Prev Med 51(1): 50-55.

Pubmed | Crossref | Others

7. Wijndaele, K., Healy, G.N., Dunstan, D.W., et al. Increased cardiometabolic risk is associated with increased TV viewing time. (2010) Med Sci Sports Exerc 42(8): 1511-1518.

Pubmed | Crossref | Others

8. University of Bristol. Screen time linked to psychological problems in children. (2010) Science News.

Pubmed $\mid$ Crossref $\mid$ Others

9. Hu, F.B., Li, T.Y., Colditz, G.A., et al. Television watching and other sedentary behaviors in relation to risk of obesity and type 2 diabetes mellitus in women. (2003) JAMA 289(14): 1785-1791.

Pubmed | Crossref | Others

10. Katzmarzyk, P.T., Church, T.S., Craig, C.L., et al. Sitting time and mortality from all causes, cardiovascular disease, and cancer. (2009) Med Sci Sports Exerc 41(5): 998-1005. Pubmed | Crossref | Others

11. Teychenne, M., Ball, K., Salmon, J. Sedentary behavior and depression among adults: a review. (2010) Int J Behav Med 17(4):246-54.

Pubmed | Crossref | Others
12. Robins, R.W., Trzesniewski, K.H., Tracy, J.L., et al. Global self-esteem across the lifespan. (2002) Psychol Aging 17(3): 423-434.

Pubmed | Crossref | Others

13. McClure, A.C., Tanski, S.E., Kingsbury, J., et al. Characteristics Associated with Low Self-esteem among U.S. Adolescents. (2010) Acad Pediatr 10(4): 238-244.

Pubmed | Crossref | Others

14. Smyth, J.M. Beyond self-selection in video game play: an experimental examination of the consequences of massively multiplayer online role-playing game plays. (2007) Cyber psychol Behav 10(5): 717-721.

Pubmed | Crossref | Others

15. Breland, J.Y., Fox, A.M., Horowitz, C.R. Screen time, physical activity and depression risk in minority women. (2013) Ment Health Phys Act 6(1): 10-15.

Pubmed | Crossref | Others

16. Arredondo, E.M., Lemus, H., Elder, J., et al. The relationship between sedentary behavior and depression among Latinos. (2013) Ment Health Phys Act 6(1): 3-9.

Pubmed | Crossref | Others

17. Webb, O.J., Benjamin, C., Gammon, C., et al. Physical activity, sedentary behaviour and physical self-perceptions in adolescent girls: a mediation analysis. (2013) Ment Health Phys Act 6(1): 24-29.

Pubmed | Crossref | Others

18. Nihill, G.F., Lubans, D.R., Plotnikoff, R.C. Associations between sedentary behavior and self-esteem in adolescent girls from schools in low-income communities. (2013) Ment Health Phys Act 6(1): 30-35.

Pubmed | Crossref | Others

19. Lubans, D.R., Hesketh, K., Cliff, D.P., et al. A systematic review of the validity and reliability of sedentary behaviour measures used with children and adolescents. (2011) Obes Rev 12(10): 781-799.

Pubmed | Crossref | Others

20. Andrew, G., Slade, T. Interpreting scores on the Kessler Psychological Distress Scale. (2001) Aust N Z J Public Health 25(6): 494-497.

Pubmed | Crossref | Others

21. Crandal R. The he measurement of self-esteem and related constructs. (1973) In J.P. Robinson \& P.R. Shaver (Eds), Measures of social psychological attitudes: 80-82.

Pubmed | Crossref $\mid$ Others

22. Rosenberg, D.E., Norman, G.J, Wagner, N, et al. Reliability and validity of the Sedentary Behaviour Questionnaire (SBQ) for adults. (2010) J Phys Act Health 7(6): 697-705. Pubmed | Crossref | Others

23. Large, A., Tedd, L.A., Hartley, R.J. Information Seeking in the Online Age: Principles and Practice. Munchen: Saur. (2011).

Pubmed | Crossref $\mid$ Others

24. Herring, S.D. Using the World Wide Web for Research: Are Faculty Satisfied? J AcadLibrariansh. 2001; 27(3): 213-219. Pubmed | Crossref $\mid$ Others

25. Park, S. Analysis of Characteristics and Trends of Web Queries Submitted to NAVER, a Major Korean Search Engine. (2009) Libr Inf Sci Res 31: 126-133.

Pubmed | Crossref $\mid$ Others 

5(1): 31- 36 .

26. Cockerton, T., Moore, S., Norman, D. Cognitive test performance and background music. (1997) Percept Mot Skills 85(2): 1435-1438.

Pubmed $\mid$ Crossref $\mid$ Others

27. Wang, X., Perry, A.C. Metabolic and physiologic responses to video game play in 7- to 10-year-old boys. (2006) Arch Pediatr Adolesc Med 160(4): 411-415.

Pubmed | Crossref | Others

28. Reichert, F.F., Baptista Menezes, A.M., Wells, J.C., et al. Physical activity as a predictor of adolescent body fatness: a systematic review. (2009) Sports Med 39(4): 279-294. Pubmed | Crossref | Others

29. Gentile, D.A., Choo, H., Liau, A., et al. Pathological video game use among youths: a two-year longitudinal study. (2011) Pediatr 127(2): 319-329.

Pubmed | Crossref $\mid$ Others

Submit your manuscript to Ommega Publishers and we will help you at every step:

- We accept pre-submission inquiries

- Our selector tool helps you to find the most relevant journal

- We provide round the clock customer support

- Convenient online submission

- Thorough peer review

- Inclusion in all major indexing services

- Maximum visibility for your research

Submit your manuscript at

https://www.ommegaonline.org/submit-manuscript 